\title{
Revision of the grandiosity dimension of the Dimensional Clinical Personality Inventory and verification of its psychometric properties
}

\author{
Revisão da dimensão grandiosidade do Inventário Dimensional Clínico da \\ Personalidade e verificação de suas propriedades psicométricas
}

Lucas de Francisco Carvalho, ${ }^{1}$ Catarina Possenti Sette, ${ }^{2}$ Bárbara Letícia Ferrari ${ }^{2}$

\begin{abstract}
Introduction: Personality disorders are among the most common disorders seen in clinical psychology. However, in Brazil there are few instruments for assessing the pathological characteristics of personality.

Objective: To revise the grandiosity dimension of the Brazilian Dimensional Clinical Personality Inventory (Inventário Dimensional Clínico da Personalidade [IDCP]) and investigate its psychometric properties.

Methods: A total of 225 people participated in this study. Their ages ranged from 18 to 66 years (mean $[\mathrm{M}]=26.2$, standard deviation $[S D]=8.1)$ and the majority were female $(n=162$, $70.1 \%$ ). The IDCP and the Brazilian versions of the Revised NEO Personality Inventory (NEO PI-R) and the Personality Inventory for DSM-5 (PID-5) were administered to all participants.

Results: A total of 285 new items were developed and content analysis was used to select 33 of these to comprise the final version destined for administration. The results of parallel analysis and factor analysis identified four interpretable factors. Internal consistency coefficients were deemed acceptable and varied from 0.73 to 0.84 for the factors. Additionally, the expected correlations between the IDCP Inventory and the other tests were observed. Conclusion: This study demonstrates the revised dimension's suitability for assessment of the pathological traits of narcissistic personality disorder.
\end{abstract}

Keywords: Personality disorders, psychometrics, personality traits.

\section{Resumo}

Introdução: Os transtornos da personalidade estão entre os distúrbios mais comuns na clínica psicológica. Porém, ainda são escassos os instrumentos para avaliação das características patológicas da personalidade no Brasil.

Objetivo: Revisar a dimensão grandiosidade do Inventário Dimensional Clínico da Personalidade (IDCP), investigando também suas propriedades psicométricas.

Métodos: Participaram do estudo 225 sujeitos com idade variando entre 18 e 66 anos [média $(M)=26,2$; desvio padrão $(D P)=8,1$, sendo a maior parte do sexo feminino $(n=162$; $70,1 \%$ ). Todos os participantes responderam O IDCP e as versões brasileiras do Inventário de Personalidade NEO Revisado (NEO PI-R) e do Personality Inventory for DSM-5 (PID-5).

Resultados: Foram desenvolvidos 285 novos itens e selecionados, por meio de análise de conteúdo, 33 para compor a versão final de aplicação. Com base em análise paralela e análise fatorial, quatro fatores interpretáveis foram encontrados. Os coeficientes de consistência interna mostraram-se adequados, variando entre 0,73 e 0,84 para os fatores. Ainda, foram encontradas correlações esperadas entre o IDCP e os outros testes utilizados.

Conclusões: Ressalta-se a adequabilidade da dimensão revisada na avaliação de traços patológicos do funcionamento narcisista da personalidade.

Descritores: Transtornos de personalidade, psicometria, traços de personalidade.

\footnotetext{
${ }^{1}$ Programa de Pós-Graduação Stricto Sensu em Psicologia (PPG Psicologia), Universidade São Francisco (USF), Itatiba, SP, Brazil. ${ }^{2}$ Faculdade de Psicologia, USF, Itatiba, SP, Brazil.

This study was presented at XXI Encontro de Iniciação Científica, XIV Encontro de Pós-Graduação, X Encontro de Extensão Universitária, and VII Seminários de Estudos do Homem Contemporâneo, held on May 11th 2015 at Universidade São Francisco (USF), Itatiba, SP, Brazil.

Financial support: Fundação de Amparo à Pesquisa do Estado de São Paulo (FAPESP); Conselho Nacional de Desenvolvimento Cientifico e Tecnológico (CNPq). Submitted Aug 06 2015, accepted for publication Feb 04 2016. No conflicts of interest declared concerning the publication of this article.

Suggested citation: Carvalho LF, Sette CP, Ferrari BL. Revision of the grandiosity dimension of the Dimensional Clinical Personality Inventory and verification of its psychometric properties. Trends Psychiatry Psychother. 2016;38(3):147-155. http://dx.doi.org/10.1590/2237-6089-2015-0040
} 


\section{Introduction}

According to current data available in the scientific literature, personality disorders are among the most frequently treated disorders in psychology clinical practice. ${ }^{1,2}$ This scenario creates a need for assessment tools specifically aimed at pathological personality traits. In Brazil, however, there are few instruments available for broad assessment of pathological personality traits, i.e., instruments that take into consideration the diverse factors of a personality that may fall into a maladaptive range. ${ }^{3}$

It was in this context that Carvalho \& Primi $^{6}$ developed the Dimensional Clinical Personality Inventory (IDCP), based on the American Psychological Association's $(\mathrm{APA})^{4}$ diagnostic criteria for personality disorders and on the symptomology of these disorders that is frequently observed in clinical practice. ${ }^{5}$ The inventory is a self-report instrument for assessment of pathological personality traits consisting of 163 items divided into 12 dimensions. Each dimension relates to a particular pathological personality trait (for instance, borderline and antisocial). Data currently available attest to the psychometric suitability of the IDCP dimensions, which can be observed in terms of the inventory's internal consistency reliability index. Its validity is also evidenced by its internal structure and by external variables. ${ }^{6-10}$ However, Carvalho \& Primi ${ }^{6}$ have identified a need to revise the instrument's dimensions, including updating its scope of assessment in the light of recently published literature. ${ }^{1}$

This study aims to do just that, focusing on revising the IDCP grandiosity dimension, which is mainly used to assess the common traits of narcissistic personality disorder (NPD). ${ }^{9}$ This dimension includes feelings of pleasure obtained from external recognition, an excessive need for being admired by others, and underlying beliefs of self-worth and superiority. These feelings generate self-entitlement, grandiosity, and distrust/persecution reactions towards others.

The proponents of the hybrid model for the Diagnostic and Statistical Manual of Mental Disorders, 5th edition $(D S M-5)^{1}$ retained NPD, which can be found in Section 3 and Section 2, and preserved the structure of the previous DSM edition. According to DSM-5, NPD can be characterized by an invasive grandiosity pattern (manifest in both fantasy and behavior), admiration seeking, and lack of empathy. An person who is diagnosed with NPD exhibits a high sense of self-importance (related to their desire to be recognized as a superior individual), is preoccupied with power, brilliance, beauty, or ideal love. They also believe themselves to be unique and, thus, require excessive admiration and exhibit arrogant behaviors and attitudes. These symptoms begin to show in adulthood, in a variety of settings. ${ }^{1}$

Moreover, a person who is diagnosed with NPD will generally also exhibit significant personality deficiencies, due to impaired identity self-functioning, such as excessive references to others for self-definition, selfesteem and emotional regulation, and exaggerated self-appraisal. They may also exhibit an impaired selfdirection process, which would mean that their goal setting would be based on gaining approval from others; their personal standards are too high (so they may perceive themselves as a very special individual) or too low (as they may be unaware of their own motivations). Interpersonal functioning is also impaired. These people will often lack empathy, exhibit egocentric behavior, and excessively seek attention in an attempt to attract and be the focus of external attention. ${ }^{1}$ Millon et al. ${ }^{11}$ point out that narcissists are known for their lack of empathy, which can impair the relationships they establish, especially amorous relationships, where their partner may be perceived as a mere support for the narcissistic ego. These authors point out that narcissists will often make a good first impression, but can be subsequently viewed as arrogant because they present a cool and confident exterior. They are also highly sensitive and seek out people who admire them.

Narcissistic personality disorder is the personality disorder (PD) with the lowest frequency of occurrence in the general population, with a median prevalence of $0.5 \%$ across 12 studies according to a review conducted in 2009. ${ }^{12}$ Only the recent National Epidemiologic Survey on Alcohol and Related Conditions (NESARC, wave 2, not included in the review cited above) reported a high prevalence rate $\left(6.2 \%\right.$, 2nd most common). ${ }^{13}$ In clinical settings, NPD has been found to be moderately common $(5.7 \%),{ }^{14,15}$ but still less common than the average PD $(9.3 \%) .{ }^{13}$ Additionally, in a study referred to as the Managing Impacts of Deep-sea Resource Exploitation (MIDAS) project, NPD was the fifth most frequent diagnoses recorded in a sample of 2,151 psychiatric patients, ${ }^{16}$ further demonstrating the moderate prevalence of this disorder in clinical samples.

In the field of empirical research, Abela ${ }^{17}$ conducted a study in Brazil to investigate the profiles of patients diagnosed with personality disorders. Considering all comorbidities related by the participants, she states that the results reveal a narcissistic profile characterized by a high degree of grandiosity and attention seeking (exaggerated need for external attention, seduction, and disproportionate reactions, in addition to overtly seeking friendships). The results confirm the relevance of these dimensions to narcissistic personality disorder, given that they are in line with the definitions set out in the DSM-5. 
This study was conducted to extend studies of the IDCP grandiosity dimension, replicating procedures used in a series of studies to revise other IDCP dimensions. ${ }^{18-22}$ The objective is to revise the grandiosity dimension and verify the psychometric properties of the revised version of the dimension. We have also sought to establish specific profiles based on the revised dimension's factors that should make it possible to differentiate between individuals who have similar overall dimension scores, but exhibit distinct traits within the dimension.

\section{Method}

The description of the methods has been divided into two parts to better meet this study's objectives. Initially (Part I), we detail the procedures employed for revision of the IDCP grandiosity dimension. Then (Part II), we present data from an empirical verification of the new dimension's psychometric properties.

\section{Procedures for revision of the grandiosity dimension (Part I)}

The objective of revising the dimension was to formulate a new set of items for administration and this was achieved by a six-phase process that replicates procedures previously adopted to revise other dimensions of the IDCP. ${ }^{23-25}$ The first phase consists of reviewing significant literature in the area. Four sources were used for this: the DSM $-5,{ }^{1}$ the dimensions of the Personality Inventory for DSM-5 (PID-5), ${ }^{23}$ the dimensions assessed by the Shedler-Westen Assessment Procedure (SWAP), ${ }^{24}$ and Anna Clark's dimensions, ${ }^{25}$ which are included in the Schedule for Nonadaptive Personality (SNAP). The literature review sought to identify traits related to the grandiosity dimension and to narcissistic personality disorder. In Phase II, constructs and dimensions pertaining to the IDCP dimension and to typical narcissistic personality traits were selected and organized in an electronic spreadsheet, based on the references reviewed in Phase I. The definitions and sentences selected were input to the spreadsheet in their original language (i.e., English) and then the authors of the present study translated them independently before coming to a consensus on the final version of each translation. This procedure was based on recommendations made by Beaton et al., ${ }^{26}$ but greater flexibility was allowed since our aim was not to translate and culturally adapt a psychological test.

The third phase comprised operationalization of the constructs selected. This consisted of development of new items for the grandiosity dimension, based on the traits organized in the spreadsheet described above. Subsequently, in Phase IV, the researchers individually selected the items they believed to be most appropriate from a conceptual standpoint, and then these selections were compared so that a consensus could be reached on which items should be kept in the final version destined for administration.

In Phase V, the items were grouped in categories according to their content, along with the items from the dimension's original version. Thus, the content assessed by the new and the original items could be compared. Redundant items were excluded as part of this phase. In the last phase, we made the final selection of which new items would comprise the final version of the revised grandiosity dimension (this phase will become clearer in the Results session).

\section{Determination of the psychometric pro- perties of the grandiosity dimension (Part II)}

\section{Participants}

Two hundred and twenty-five participants were selected by convenience. They were aged between 18 and 66 years $($ mean $[\mathrm{M}]=26.2$, standard deviation $[\mathrm{SD}]=$ $8.1), 162$ of them were female $(70.1 \%)$, and the majority were undergraduate students (58.9\%). Participants who had a history of psychiatric/psychological treatment were identified. Of these, 68 reported having undergone psychotherapy, 12 had had psychiatric treatment and 11 had taken psychotropic medications. The only inclusion criterion was to be aged over 18 .

\section{Instruments}

Three instruments were administered for this study. The IDCP, $^{6}$ the Brazilian version of the Revised NEO Personality Inventory (NEO PI-R), ${ }^{27}$ and the Brazilian version of the PID-5.23

The IDCP is a self-report instrument developed for assessment of pathological personality traits based on the theories of Millon ${ }^{5,11}$ and on diagnostic criteria from axis II of the Diagnostic and Statistical Manual of Mental Disorders (DSM-IV-TR ${ }^{4}$ ). Originally, the instrument comprised 163 items with responses arranged along a 4-point Likert scale, where 1 stands for "has nothing to do with me" and four for "everything to do with me," with an average time of administration of 25 minutes. The items cover the 12 IDCP personality dimensions, namely: dependency, aggressiveness, mood instability, eccentricity, need for attention, distrust, grandiosity, isolation, criticism avoiding, self-sacrifice, conscientiousness and impulsivity. Studies have shown 
the adequacy of the IDCP dimensions' psychometric properties $^{6-10,17}$ including evidence of validity based on internal structure (Classical Test Theory and Item Response Theory) and based on relationships to external variables (NEO PI-R and psychiatric diagnosis), and reliability coefficients for internal consistency.

The NEO PI-R is a self-report inventory focused on evaluation of adult personality comprising 240 items with responses arranged along a 5-point Likert scale, ranging from 1 (strongly disagree) to 5 (strongly agree) and an administration time of approximately 25 minutes. The instrument covers five dimensions of personality: neuroticism, extraversion, openness, agreeableness and conscientiousness. However, for this study we only used the neuroticism and agreeableness dimensions, in view of the dimension being revised. The manual for the Brazilian version lists studies demonstrating evidence of validity and satisfactory reliability indices. ${ }^{27}$ It should be noted that the NEO PI-R was developed to assess healthy personality's traits ${ }^{27}$ and as such it does not include a dimension that directly relates to narcissistic functioning. In view of this we chose to investigate correlations with the dimensions and facets that are more closely related, i.e., neuroticism (as it is more closely related to less healthy traits) and agreeableness (negative reactions to interpersonal difficulties), typically present in narcissistically functioning people. ${ }^{5}$

The PID-5 is a self-report inventory developed for assessing the pathological characteristics of personality contained in criterion B of personality disorders categorized in section 3 of the DSM- $5 .{ }^{1}$ It consists of 220 items that should be answered on a 4-point Likert scale, with 0 equal to "false or often false" and 3 equal to "true or often true." The PID- 5 assesses 25 facets, grouped into five dimensions: negative affect, detachment, antagonism, disinhibition and psychoticism. However, in this study the focus was on the facets callousness, deceitfulness, grandiosity, and manipulativeness. No studies were found that have determined the psychometric properties of the Brazilian version of the PID-5, but Krueger et al. ${ }^{23}$ have published data that indicate the suitability of the original version of the test.

\section{Procedures}

After submission to and approval by the Research Ethics Committee (CAAE: 21992113.1.0000.5514), data collection was initiated at a private university in the state of São Paulo, Brazil. The instruments were administered in groups, with a duration of approximately 40 minutes per session per class. As necessary, some participants completed the instruments individually at private establishments. The instruments were administered after explanation of the research objectives and after participants had signed consent forms.

The data collected were analyzed statistically. In order to achieve the study objectives, the first step was to compute how many factors would be retained in the exploratory factor analysis, using parallel analysis. ${ }^{28,29}$ This analysis was conducted using $\mathrm{R}$ software (version 2.15.3), since it offers parallel analysis for polychoric variables, which is the case in the present study.

Next, a database was created for Mplus software (version 6.12), in order to conduct an exploratory factor analysis with polychoric variables using exploratory structural equation modeling (ESEM) and to calculate fit indices to indicate the suitability of the structure identified based on this sample. It is also worth noting that goodness of fit indices also indicate the sample's suitability for analysis. The method chosen was Geomin rotation, since it is oblique and offers correlations between factors in the software output, and the likelihood estimator was used with robust standard errors (robust maximum likelihood), given the number of items. Finally, we conducted analyses of correlations between the factors extracted for the grandiosity dimension, the factors and facets of the NEO PI-R and the facets of the PID-5.

\section{Results}

In Part I, the literature review of the most relevant traits for the grandiosity dimension took several constructs into consideration, including feelings of grandiosity, manipulativeness, ${ }^{1,23}$ narcissism, ${ }^{24}$ distrust, grandiose egocentrism, emotional coldness, exhibitionism, selfabsorption, and instability. ${ }^{25}$

This specialized literature review was used by the researchers to independently create items, resulting in 285 items. These items were subsequently selected based on criteria such as clarity, coherence, and coverage of content that had not been sufficiently represented in the original grandiosity dimension. This phase resulted in a set of 58 preselected items. Next, in an attempt to reduce the number of items using the criterion of elimination of redundant items, the researchers conducted another selection process which arrived at a total of 33 items. The resultant revised version of the grandiosity dimension contained 33 new items plus 12 original items, grouped in four categories created by the authors: superiority (14 new and 8 original items), exhibitionism ( 4 new items and 1 original), other-derogation (4 new items and 1 original), and manipulativeness ( 9 new items). Two original items (related to narcissist delusions of persecution) did not fit into any of the categories. These categories were created on the basis of item content solely 
for the purpose of verification of global characteristics evaluated by the set of items.

Next, in Part II, the psychometric properties of the 45item set were investigated, starting by applying parallel analysis for polychoric variables, with the objective of determining the maximum number of factors for the set of items. Seven factors had high eigenvalues that were not randomly evidenced. This was followed by an exploratory factor analysis with fit indices (ESEM), forcing multi-factor solutions (two to seven) with oblique Geomin rotation and a robust maximum likelihood extraction method, believed to be a robust method suitable for polychoric variables. Based on this data, the fit indices generated for the six factorial solutions were analyzed. The four-factor model was found to be the most appropriate, taking into consideration the results for $\chi^{2} /$ degrees of freedom $(\mathrm{df})=1952.943 / 816$; root mean square error of approximation (RMSEA) $=0.082$ (acceptable); comparative fit index (CFI) $=0.664$ (poor); and standardized root mean square residual (SRMR) = 0.057 (good), in addition to interpretation of the observed set of items. Factor loadings, the number of items kept for each factor, and internal consistency indices (Cronbach's alpha) can be seen in Table 1. Items retained for each factor are shown in bold.

The final version of the revised grandiosity dimension comprised 18 items (14 new items) divided into four factors, with four to five items per factor. The number of items per factor was kept to a minimum in an attempt to prevent the instrument from becoming too extensive and exhaustive, since the IDCP contains 12 dimensions and should mainly be utilized in clinical settings. Therefore, the following four criteria were used to exclude some of the items (which were deemed to have acceptable properties for exclusion): (a) item impairs or has a negative impact on factor's internal consistency, (b) item presents too little interpretative consistency to be kept in the factor, (c) significant loadings in more than one factor (difference lower than 0.50 in intra-factor loadings), and (d) content redundancy between items in the same factor. All factors had internal consistency coefficients greater than 0.73 . The entire dimension was found to have an index of 0.87 for the full set of 18 items.

After defining the internal structure, the dimension's factors and total score were related and compared to the original dimension and to the NEO PI-R and PID-5 dimensions and facets. Table 2 shows the results of the correlations between the factors and the total score of the revised dimension when compared to the original and also total scores for the neuroticism and agreeableness dimensions of the NEO PI-R.

Table 1 - Exploratory factor analysis and internal consistency indices

\begin{tabular}{|c|c|c|c|c|}
\hline Items & Need for recognition & Superiority & Dominance & Indifference \\
\hline 59 & 0.34 & 0.70 & 0.33 & 0.17 \\
\hline 62 & 0.62 & 0.46 & 0.45 & 0.43 \\
\hline 96 & 0.78 & 0.38 & 0.30 & 0.41 \\
\hline 115 & 0.61 & 0.39 & 0.28 & 0.47 \\
\hline 587 & 0.26 & 0.28 & 0.58 & 0.09 \\
\hline 592 & 0.33 & 0.80 & 0.32 & 0.37 \\
\hline 594 & 0.54 & 0.43 & 0.45 & 0.45 \\
\hline 596 & 0.32 & 0.60 & 0.44 & 0.49 \\
\hline 597 & 0.37 & 0.70 & 0.32 & 0.35 \\
\hline 598 & 0.49 & 0.64 & 0.33 & 0.30 \\
\hline 605 & 0.30 & 0.26 & 0.38 & 0.47 \\
\hline 606 & 0.23 & 0.12 & 0.19 & 0.35 \\
\hline 607 & 0.18 & 0.23 & 0.19 & 0.48 \\
\hline 610 & 0.14 & 0.33 & 0.27 & 0.70 \\
\hline 611 & 0.15 & 0.14 & 0.66 & 0.19 \\
\hline 612 & 0.18 & 0.26 & 0.60 & 0.20 \\
\hline 615 & 0.11 & 0.36 & 0.58 & 0.39 \\
\hline 616 & 0.11 & 0.31 & 0.57 & 0.25 \\
\hline Items (initial) & 12 & 11 & 6 & 9 \\
\hline Items (final) & 4 & 5 & 5 & 4 \\
\hline$\alpha$ (initial) & 0.87 & 0.88 & 0.78 & 0.81 \\
\hline$\alpha$ (final) & 0.84 & 0.82 & 0.76 & 0.73 \\
\hline
\end{tabular}


Table 2 - Factor correlation results, total scores, and NEO PI-R facets

\begin{tabular}{|c|c|c|c|c|c|c|c|c|}
\hline & F1 & F2 & F3 & F4 & RG & OG & $\mathbf{N}$ & $\mathbf{A g}$ \\
\hline $\mathrm{F} 1$ & 1 & $0.57 *$ & $0.33 *$ & $0.43 *$ & $0.78 *$ & $0.84 *$ & $0.33 *$ & $-0.35 *$ \\
\hline $\mathrm{F} 2$ & $0.57 *$ & 1 & $0.34 *$ & $0.36 *$ & $0.80 *$ & $0.69 *$ & $0.19 *$ & $-0.28^{*}$ \\
\hline F3 & $0.33 *$ & $0.34 *$ & 1 & $0.29 *$ & $0.70 *$ & $0.35^{*}$ & 0.01 & $-0.14 \dagger$ \\
\hline F4 & $0.43 *$ & $0.36 *$ & $0.29 *$ & 1 & $0.65^{*}$ & $0.41^{*}$ & $0.18^{*}$ & $-0.35^{*}$ \\
\hline RG & $0.78 *$ & $0.80 *$ & $0.70 *$ & $0.65^{*}$ & 1 & $0.77^{*}$ & $0.24 *$ & $-0.35^{*}$ \\
\hline OG & $0.84 *$ & $0.69 *$ & $0.35^{*}$ & $0.41 *$ & $0.77 *$ & 1 & $0.48^{*}$ & $-0.42 *$ \\
\hline $\mathrm{N}$ & $0.33 *$ & $0.19 *$ & 0.01 & $0.18^{*}$ & $0.24 *$ & $0.48 *$ & 1 & $-0.53 *$ \\
\hline $\mathrm{Ag}$ & $-0.35^{*}$ & $-0.28 *$ & $-0.14 \dagger$ & $-0.35 *$ & $-0.35 *$ & $-0.42 *$ & $-0.53 *$ & 1 \\
\hline
\end{tabular}

F1 = need for recognition; F2 = superiority; F3 = dominance; F4 = indifference; Ag = agreeableness; $\mathrm{N}=$ neuroticism; NEO PI-R = Revised NEO Personality Inventory; $O G=$ original grandiosity dimension; $R G=$ revised grandiosity dimension.

$* \mathrm{p} \leq 0.01 ;+\mathrm{p} \leq 0.05$.

As shown in Table 2, factor correlations varied from 0.29 to 0.57 and the revised dimension's total score varied from 0.65 to 0.80 . Correlations for the original dimension varied from 0.35 to 0.84 . The table also shows that neuroticism correlated positively and significantly with all factors except dominance and with the total scores for both original and revised dimensions. The strongest correlations with neuroticism were for the original dimension score and Factor 1 , need for recognition, with coefficients of 0.48 and 0.33 respectively. Agreeableness had negative and statistically significant correlations and the highest coefficients were for the correlations with need for recognition ( $r=-0.35)$, indifference $(r=-0.35)$, and the original dimension score $(r=-0.42)$. The factors superiority, dominance, and indifference had the strongest correlations with the revised dimension, while need for recognition had a stronger correlation with the original dimension. Table 3 lists the results for correlations between the original dimension, the revised dimension, and the four factors in relation to the neuroticism and agreeableness dimensions of the NEO PI-R and the facets of the PID-5.

As shown in Table 3, correlations between the revised grandiosity dimension's factors and total score and the facets of the NEO PI-R neuroticism dimension did not exceed 0.40 . These values suggest that none of the neuroticism facets are directly related to the content of the factors. Furthermore, depression was the neuroticism facet that exhibited the strongest correlation with total

Table 3 - Correlations between the original and revised dimensions and the NEO PI-R and the PID-5

\begin{tabular}{|c|c|c|c|c|c|c|}
\hline Factors & F1 & $\mathbf{F 2}$ & F3 & F4 & RG & OG \\
\hline \multicolumn{7}{|l|}{ Neuroticism } \\
\hline Anxiety & $0.26 *$ & 0.12 & 0.02 & 0.10 & $0.17+$ & $0.38^{*}$ \\
\hline Anger/hostility & $0.28^{*}$ & $0.18 *$ & -0.08 & $0.14 \dagger$ & $0.16 \dagger$ & $0.40^{*}$ \\
\hline Depression & $0.33^{*}$ & $0.24 *$ & 0.03 & $0.22 *$ & $0.28 *$ & $0.46^{*}$ \\
\hline Self-consciousness/embarrassment & $0.20 *$ & $0.17 *$ & -0.01 & $0.14+$ & $0.15+$ & $0.28 *$ \\
\hline Impulsiveness & $0.19 *$ & 0.07 & $0.17^{*}$ & 0.08 & $0.19 *$ & $0.29 *$ \\
\hline Vulnerability & $0.21 *$ & 0.05 & -0.02 & 0.12 & 0.11 & $0.31^{*}$ \\
\hline \multicolumn{7}{|l|}{ Agreeableness } \\
\hline Trust & $-0.27 *$ & $-0.25^{*}$ & -0.07 & $-0.23 *$ & $-0.26 *$ & $-0.38 *$ \\
\hline Straightforwardness & $-0.27 *$ & $-0.13+$ & $-0.25 *$ & $-0.26 *$ & $-0.27 *$ & $-0.25^{*}$ \\
\hline Altruism & $-0.19 *$ & $0.15+$ & 0.06 & $-0.28 *$ & $-0.17+$ & $-0.25 *$ \\
\hline Compliance & $-0.22 *$ & -0.10 & $-0.17^{*}$ & $-0.15+$ & $-0.22 *$ & $-0.30 *$ \\
\hline Modesty & $-0.30 *$ & $-0.31 *$ & -0.11 & $-0.16+$ & $-0.29 *$ & $-0.29 *$ \\
\hline Tender-mindedness & -0.11 & $-0.14 \dagger$ & -0.01 & $-0.27 *$ & $-0.14 \dagger$ & $-0.15+$ \\
\hline \multicolumn{7}{|l|}{ PID-5 } \\
\hline Callousness & $0.37^{*}$ & $0.36 *$ & $0.27^{*}$ & $0.66 *$ & $0.55^{*}$ & $0.44^{*}$ \\
\hline Deceitfulness & $0.32 *$ & $0.33^{*}$ & $0.22 *$ & $0.33^{*}$ & $0.40 *$ & $0.38^{*}$ \\
\hline Grandiosity & $0.43 *$ & $0.50 *$ & $0.25^{*}$ & $0.36^{*}$ & $0.54 *$ & $0.39 *$ \\
\hline Manipulativeness & $0.38 *$ & $0.35^{*}$ & $0.51 *$ & $0.33 *$ & $0.54^{*}$ & $0.43^{*}$ \\
\hline
\end{tabular}

$\mathrm{F} 1=$ need for recognition, F2 $=$ superiority, F3 = dominance, F4 = indifference; NEO PI-R = Revised NEO Personality Inventory; OG = original grandiosity dimension; PID-5 = Personality Inventory for DSM-5; RG = revised grandiosity dimension.

$* \mathrm{p} \leq 0.01 ;+\mathrm{p} \leq 0.05$. 
scores, both for the revised and the original versions of the grandiosity dimension, with coefficients of 0.28 and 0.46 respectively. Correlations with the agreeableness facets were slightly stronger than the correlations with neuroticism. All correlations were negative and of lowmagnitude, most of them statistically significant. Table 3 also shows that the strongest correlations with the factors need for recognition and superiority were for the modesty facet; while the strongest correlation with the dominance factor was for straightforwardness; and the strongest correlation with the indifference factor was for the altruism facet. The total revised dimension score was most strongly related to the modesty facet and the original dimension total score exhibited its highest correlation with the trust facet. Still with relation to the results shown in Table 3, the PID-5 facets exhibited higher magnitude correlations than the NEO PI-R dimensions. The strongest correlations with the factors need for recognition and superiority was for the PID-5 grandiosity facet. The strongest correlation with the dominance factor was for PID-5 manipulativeness, and the strongest correlation with the indifference factor was with the PID-5 callousness facet. The total score for the revised grandiosity dimension exhibited values that were similar to those of the PID-5 facets. The original dimension's total score also exhibited similar values, but they were lower than for the revised dimension.

\section{Discussion}

The original IDCP grandiosity dimension covers traits such as belief in self-worth and superiority, obtaining pleasure from external recognition, admiration seeking, and reactions involving other-derogation, distrust, and persecution delusion. ${ }^{9}$ According to Abela ${ }^{17}$ and to Carvalho \& Primi, ${ }^{6}$ this dimension relates most closely to narcissistic personality disorder, which is expected given this disorder's diagnostic criteria. ${ }^{1}$ This study aimed to further refine the grandiosity dimension and update it to include pathological traits typically related to narcissistic personality disorder. In order to achieve this, we developed 285 new items based on a literature review. . $^{123-25}$ We then selected 33 of these items for administration (based on criteria described previously), including the superiority, exhibitionism, otherderogation, and manipulativeness constructs.

This new set of items was administered along with the original set and a final version of the revised grandiosity dimension was constructed after analysis of the data obtained. This version consists of 18 items, including 4 original and 14 new items. These items were divided into four factors, namely: need for recognition (four items), superiority (five items), dominance (five items), and indifference (four items), which exhibited acceptable internal consistency coefficients. ${ }^{30}$ The revised dimension's total score also had acceptable internal consistency ( $\alpha=$ $0.87)$, similar to the original version ( $\alpha=0.86)$, as observed by Carvalho $\&$ Primi. ${ }^{9}$ The need for recognition factor can be defined as one's need to be the center of attention and to have one's own qualities recognized, illustrated by the following item: "I feel like I still don't get all of the recognition I deserve." The second factor, superiority, consists of feelings of being targeted by other people's envy due to one's own qualities and believing oneself to be better than others, as illustrated by the following item: "I know it bothers people that I'm better than them." The dominance factor relates to manipulativeness and to how easily a person believes they can have things done their way, as illustrated by: "I know how to talk to people to get what I want." Lastly, the indifference factor reflects a person's lack of interest in other people's problems and their belief that only their problems or hardships are relevant, as illustrated by the following: "It's hard for me to care about other people's suffering." The factors identified are consistent with the reference literature, ${ }^{1,23-25}$ which suggests evidence of validity based on the revised dimension's internal structure and presents acceptable error levels, as evidenced via internal consistency.

Additionally, a low and moderate intra-correlation between the factors of the revised dimension was also observed, which suggests that distinct profiles may be established within the grandiosity dimension. This result indicates that people with similar overall scores in the dimension may, at times, present different internal factor scores, making it possible to specifically differentiate these individuals.

In the original version of the grandiosity dimension the correlations between the factors dominance, indifference, and superiority and total score were weaker than the equivalent correlations in the revised version, indicating that the revised dimension now represents these traits better. The need for recognition factor exhibited the highest correlation with the original dimension, suggesting that this construct was already covered in the previous version. A correlation of moderate magnitude was found between the revised dimension and the original dimension, which suggests that their sets of items are related, but that there are changes in the traits being assessed, i.e., some constructs were not being assessed in the original dimension. Additionally, there were high values for correlations between the revised dimension's total score and the observed factors of the revised dimension, indicating a subjacent construct between factors, in this case, grandiosity. We also observed that correlations between the factors of the revised grandiosity dimension ranged from low to moderate, which suggests the possibility of discriminating individuals into profiles within the grandiosity dimension, and which should 
be verified in future studies and may be of great value for applications of the IDCP in clinical settings.

With regard to correlations between the IDCP and the other instruments administered, it should be considered that the NEO PI-R was developed to assess healthy personality traits $^{27}$ and, as such, does not contain any dimensions that directly relate to narcissistic functioning. The neuroticism dimension had a stronger correlation with the score for the original grandiosity dimension than with the score for the revised dimension. At first appraisal this would seem to suggest, that the original score tends to be more pathological when compared to the revised grandiosity score, given that neuroticism assesses traits of a less healthy personality. ${ }^{27}$ However, a more detailed analysis of these data and of the data obtained with the PID-5 suggests otherwise. The original score exhibited lower magnitude correlations with the PID- 5 facets than the revised score, while the original score's correlations with the NEO PI-R dimensions were stronger. According to these instruments' focus of assessment (PID- 5 and NEO PI-R), it can be postulated that the relationships between the revised grandiosity score (IDCP) and the neuroticism factors (NEO PI-R) were weaker than the original score's correlations, given that: (a) the neuroticism factors do not directly assess constructs that are typically related to grandiosity, and (b) neuroticism's assessment capabilities are more moderately than extremely oriented to the grandiosity construct; and do not therefore closely reflect a personality that presents extreme functioning. Furthermore, the factor from the revised dimension that exhibited the strongest correlation with the neuroticism dimension was need for recognition, which is an expected result, given that data in the literature indicate that individuals who have an exaggerated need for recognition and admiration generally present higher levels of anger, anxiety, and impulsive behavior, all of which are assessed by the neuroticism dimension. ${ }^{31}$

All correlations with the NEO PI-R agreeableness dimension were negative, supporting data found in the literature review and providing evidence in favor of the revised dimension, since the NEO PI-R assesses healthy personality traits, while the IDCP assesses pathological traits. It is noteworthy that the same interpretation put on the results for the NEO PI-R neuroticism dimension can also be applied to the results observed for agreeableness, since this factor relates to healthy traits. The strongest (negative) correlations with agreeableness were for indifference, need for recognition, and superiority, which is to be expected, given that these factors cover traits such as little interest in other people's lives, exaggerated need for attention, and a high level of need for recognition and admiration, and given that the traits assessed by the agreeableness dimension include altruism, compliance, and tender-mindedness. ${ }^{32}$

Correlations between the IDCP dimensions and the PID-5 were also stronger than correlations with the NEO PI-R, and the revised dimension exhibited stronger correlations than the original version. Data indicate that this IDCP dimension usually assesses the pathological traits of personality and so does the PID-5. As such, the relationships observed also provide evidence suggestive of the study's validity based on an external criterion (i.e., the PID-5 dimensions). Specifically, the highest correlation coefficients for the factors need for recognition and superiority were for the PID-5 grandiosity facet, which is supported by the fact that these factors relate to a need for external attention and extreme admiration seeking. The highest correlation for dominance was with manipulativeness, which is supported by the fact that these are both traits that relate to people putting themselves in a position of power over others. The strongest correlation for indifference (IDCP) was with the PID-5 facet callousness, indicating that both assess similar traits, such as lack of interest in other people's problems and the belief that only one's own problems are relevant. Correlations observed between the IDCP grandiosity dimension's factors and the PID-5's facets are also evidence of the validity of the revised dimension, suggesting that this set of items assesses traits typical of a narcissistically functioning personality. However, considering the nature of the sample assessed, further research must be done seeking to replicate these results in clinical samples.

\section{Conclusion}

The aim of the present study - to revise the grandiosity dimension and to verify the psychometric properties of the new version - was successfully achieved, providing evidence suggestive of the validity of the revised dimension and producing acceptable coefficients of internal consistency. Furthermore, the IDCP items have been updated to include aspects representative of a more pathological state of mental functioning, i.e., the result of this study is a revised dimension that is suitable for establishing profiles when assessing narcissistic personality disorder or other disorders in which grandiosity plays a relevant role. Specifically, we have observed data suggesting that the revised version is better than the original dimension, since (a) its reliability is as good as the original, (b) the reliability of the factors is high even with just a few items, (c) the new item set offers the possibility of profile verification, and (d) correlations with the other tests, particularly the PID-5, were adequate. However, 
future studies should seek to identify the profiles and to apply this revised dimension to psychiatric patients with personality disorders.

The limitations of the present study include the number of participants and their characteristics, given that it was a limited population that does not include patients with a known diagnosis of personality disorder. We suggest that future studies replicate the structure with different populations, focusing on the relevance of clinical samples.

\section{References}

1. American Psychiatric Association. Diagnostic and Statistical Manual of Mental Disorders, Fifth Edition (DSM-5). Arlington: American Psychiatric Publishing; 2013.

2. Zuccolo PF, Corchs F, Savoia MG. Psicopatologias e o conceito da personalidade. In: Carvalho LF, Primi R. Perspectivas em psicologia dos transtornos da personalidade. São Paulo: Casa do Psicólogo; 2013. p. 8-23.

3. Carvalho LF, Bartholomeu D, Silva MCR. Instrumentos para avaliação dos transtornos da personalidade no Brasil. Aval Psicol. 2010;9:289-98.

4. American Psychiatric Association. Diagnostic and Statistical Manual of Mental Disorders, Fourth Edition, Text Revision (DSMIV-TR). Arlington: American Psychiatric Publishing; 2003.

5. Millon T. Disorders of Personality: introducing a DSM/ICD spectrum from normal to abnormal. New Jersey: Wiley; 2011

6. Carvalho LF, Primi R. Desenvolvimento e Investigação da Estrutura Interna do Inventário Dimensional Clínico da Personalidade (IDCP). Psicol Reflex Crit. 2015;28:322-30.

7. Abela RK, Carvalho LF, Cho SJM, Yazigi L. Validity evidences for the dimensional clinical personality inventory in outpatient psychiatric sample. Paidéia (Ribeirão Preto). 2015;25:221-8.

8. Carvalho LF, Oliveira Filho AQ, Pessotto F, Bortolotti SLV. Application of the unfolding model to the Aggression Dimension of the Dimensional Clinical Personality Inventory (IDCP). Rev Colomb Psicol. 2014;23:339-49.

9. Carvalho LF, Primi R. Prototype matching of personality disorders with the Dimensional Clinical Personality Inventory. Psic Teor Pesq. Forthcoming 2016.

10. Carvalho LF, Primi R, Stone GE. Psychometric properties of the Inventário Dimensional Clínico da Personalidade (IDCP) using the Rating Scale Model. Av Psicol Latinoam. 2014;32:433-46.

11. Millon T, Millon CM, Meagher S, Grossman S, Ramanath R. Personality disorders in modern life. New Jersey: Wiley; 2004

12. Torgersen S. Prevalence, sociodemographics, and functional impairment. In: Oldham JM, Skodol AE, Bender DS. Essentials of personality disorders. Washington: American Psychiatric Publishing; 2009. p. 83-102.

13. Skodol AE, Bender DS, Morey LC, Clark LA, Oldham JM, Alarcon $R D$, et al. Personality disorder types proposed for DSM-5. J Pers Disord. 2011;25:136-69.

14. Stuart S, Pfohl B, Battaglia M, Bellodi L, Grove W, Cadoret R. The cooccurrence of DSM-III-R personality disorders. J Pers Disord. 1998;12:302-15.

15. Widiger TA, Simonsen E. Alternative dimensional models of personality disorder: finding a common ground. J Pers Disord. 2005;19:110-30.
16. Zimmerman $M$. Is there adequate empirical justification for radically revising the personality disorders section for DSM-5? Personal Disord. 2012;3:444-57.

17. Abela RK. Evidências de validade para o Inventário Dimensional Clínico da Personalidade (IDCP) com base nos perfis de participantes com diagnostico psiquiátrico [tese]. São Paulo: Universidade Federal de São Paulo; 2013.

18. Carvalho LF, Arruda W. Revisão da dimensão isolamento do Inventário Dimensional Clínico da Personalidade. Temas Psicol. 2016;24:47-61.

19. Carvalho LF, Pianowski G. Revision of the Dependency Dimension of the Dimensional Clinical Personality Inventory. Paidéia (Ribeirão Preto). 2015;25:57-65.

20. Carvalho LF, Sette CP, Capitão CG, Primi R. Propriedades psicométricas da versão revisada da dimensão necessidade de atenção do inventário dimensional clínico da personalidade. Temas Psicol. 2014;22:147-60.

21. Carvalho LF, Souza BDB, Primi R. Psychometric properties of the revised conscientiousness dimension of Inventário Dimensional Clínico da Personalidade (IDCP). Trends Psychiatry Psychother. 2014;36:23-31.

22. Souza BDB, Primi R. Revisão da dimensão conscienciosidade do Inventário Dimensional Clínico da Personalidade. CES Rev Psicol. $2014 ; 7: 1-14$.

23. Krueger RF, Derringer J, Markon KE, Watson D, Skodol AE. Initial construction of a maladaptive personality trait model and inventory for DSM-5. Psychol Med. 2012;42:1879-90.

24. Shedler J, Westen D. Dimensions of personality pathology: an alternative to the five factor model. Am J Psychiatry. 2004; $161: 1743-54$

25. Clark LA. Toward a consensual set of symptom clusters for assessment of personality disorder. In: Butcher JN, Spielberger CD. Advances in personality assessment. New Jersey: Lawrence Erlbaum Associates; 1990. p. 243-66.

26. Beaton D, Bombardier C, Guillemin F, Ferraz MB. Recommendations for the cross-cultural adaptation of health status measures. New York: American Academy of Orthopaedic Surgeons; 2002.

27. Costa PT, McCrae RR. NEO-PI-R - Inventário de Personalidade NEO Revisado. São Paulo: Vetor; 2009.

28. Hayton JC, Allen DG, Scarpello V. Factor retention decisions in exploratory factor analysis: a tutorial on parallel analysis. Organ Res Methods. 2004;7:191-205.

29. Watkins MW. Determining parallel analysis criteria. J Mod Appl Stat Methods. 2006;5:344-6.

30. Nunnally JC. Psychometric theory. New York: McGraw-Hill; 1978.

31. Widiger TA, Lowe JR. A dimensional model of personality disorder: proposal for DSM-V. Psychiatr Clin North Am. 2008;31:363-78.

32. Widiger TA, Costa PT, McCrae RR. A proposal for Axis II: diagnosing personality disorders using the five factor model. In: Costa PT, Widiger TA, editors. Personality disorders and the five factor model of personality. 2nd ed. Washington: American Psychological Association; 2002. p. 431-56.

\section{Correspondence:}

Lucas de Francisco Carvalho

Universidade São Francisco

Rua Alexandre Rodrigues Barbosa, 45

13251-900 - Itatiba, SP - Brazil

Tel. : + 55 (11) 4534.8053

E-mail: lucas@labape.com.br 